\title{
Evidence-based cerebral vasospasm management
}

\author{
George W. Weyer, B.A., Colum P. Nolan, M.R.C.S.I., AND \\ R. Loch Macdonald, M.D., Ph.D.
}

Section of Neurosurgery, Department of Surgery, University of Chicago Medical Center and Pritzker School of Medicine, Chicago, Illinois

\begin{abstract}
$\checkmark$ Cerebral vasospasm and delayed cerebral ischemia remain common complications of aneurysmal subarachnoid hemorrhage (SAH), and yet therapies for cerebral vasospasm are limited. Despite a large number of clinical trials, only calcium antagonists have strong evidence supporting their effectiveness. The purpose of this work was to perform a systematic review of the literature on the treatment of cerebral vasospasm.

A literature search for randomized controlled trials of therapies used for prevention or treatment of cerebral vasospasm and/or delayed cerebral ischemia was conducted, and 41 articles meeting the review criteria were found. Study characteristics and primary results of these articles are reviewed.

Key indicators of quality were poor when averaged across all studies, but have improved greatly over time. The only proven therapy for vasospasm is nimodipine. Tirilazad is not effective, and studies of hemodynamic maneuvers, magnesium, statin medications, endothelin antagonists, steroid drugs, anticoagulant/antiplatelet agents, and intrathecal fibrinolytic drugs have yielded inconclusive results.

The following conclusions were made: nimodipine is indicated after SAH and tirilazad is not effective. More study of hemodynamic maneuvers, the effectiveness of other calcium channel antagonists such as nicardipine delivered by other routes (for example intrathecally), magnesium, statin drugs, endothelin antagonists, and intrathecal fibrinolytic therapy is warranted. There is less enthusiasm for the study of steroid drugs and anticoagulant/antiplatelet agents because they entail more risks and investigations so far have shown little evidence of efficacy. The study of rescue therapy such as balloon angioplasty and intraarterial vasodilating agents will be difficult. The quality of clinical trials should be improved.
\end{abstract}

\section{KEY WORDS • cerebral infarction • cerebral ischemia • cerebral vasospasm • intracranial aneurysm • subarachnoid hemorrhage}

$\mathrm{D}$ ELAYED cerebral ischemia and cerebral vasospasm remain the most common and debilitating neurological complications following aneurysmal SAH. ${ }^{59}$ Twenty-five to $30 \%$ of patients who survive SAH from a ruptured intracranial aneurysm suffer from ischemic complications in the ensuing weeks, and 10 to $15 \%$ of patients with SAH die or experience permanent disability due to their ischemic deficits. ${ }^{25,34}$ Although there is some controversy regarding the correlation between cerebral vasospasm in large arteries and cerebral ischemia, vasospasm remains one of the primary causes of DINDs. ${ }^{41,56}$

Proven therapeutic options for the treatment and/or prevention of delayed cerebral ischemia or cerebral vasospasm are few. Suarez, et al. ${ }^{59}$ summarized current treatment recommendations for vasospasm as consisting of prophylactic nimodipine; hypervolemia with induced hypertension, usually following the onset of vasospasm with neurological deficits; and a potential for balloon angioplasty or directed application of vasodilating agents.

Due to the emergence of the more rigorous principles of

Abbreviations used in this paper: $\mathrm{CI}=$ confidence interval; CONSORT $=$ Consolidated Standards of Reporting Trials; CT $=$ computed tomography; DINDs = delayed ischemic neurological deficits; GOS = Glasgow Outcome Scale; $\mathrm{NO}=$ nitric oxide; $\mathrm{RR}=$ relative risk; $\mathrm{SAH}=$ subarachnoid hemorrhage. evidence-based medicine, the need has arisen for a review of the available evidence on which to base the prevention and treatment of vasospasm in patients suffering from aneurysmal SAH. We have performed a systematic analysis of randomized controlled trials conducted specifically to evaluate prevention or treatment of delayed cerebral ischemia and/or cerebral vasospasm.

\section{Materials and Methods}

\section{Search Strategy}

In April 2006 we conducted a literature search of MEDLINE, the Cochrane Controlled Trials Registry, the Cochrane Stroke Trials Registry, and the National Institutes of Health/National Library of Medicine clinical trials registry, with no limitation for publication date or language. The Cochrane Controlled Trials Registry was searched using the key words "cerebral vasospasm" and "delayed cerebral ischemia." The MEDLINE Web site (www.pub med.com) was searched using the clinical query function optimized for therapy and broad search results. Search terms on MEDLINE were "cerebral vasospasm" and "delayed cerebral ischemia." Both the Cochrane Stroke Trials Registry (http://www.strokecenter.org/trials/index.aspx) and the National Institutes of Health/National Library of 
G. W. Weyer, C. P. Nolan, and R. L. Macdonald

Medicine clinical trials database (http://clinicaltrials.gov) were also searched for trials relevant to therapies for treatment and/or prevention of either cerebral vasospasm or delayed cerebral ischemia.

\section{Article Selection Criteria}

Randomized controlled trials of pharmacological or device-related therapies for prevention or treatment of cerebral vasospasm after nontraumatic aneurysmal SAH were included in the review. We only included work that would be classified as Level 1 evidence. ${ }^{8}$ Trials that lacked a control arm, presented data from a previously published paper, or focused on the incidence of vasospasm as a negative consequence of a therapy designed for another aspect of SAH (that is, tranexamic acid and antifibrinolytic therapy to prevent rebleeding) were not considered. Copies of all articles meeting the criteria were obtained and, if necessary, translated into English. Two authors read each paper and assessed whether it met the criteria for inclusion stated earlier.

\section{Statistical Analysis}

The RR with $95 \%$ CIs was calculated for outcome variables in papers in which sufficient data were provided but in which the authors did not complete the calculation themselves. The Newcombe-Wilson method was used for calculating CIs..$^{40}$ Values from articles in which the RR was reported with CIs calculated according to different or unreported methods are presented as originally described.

\section{Results}

\section{Literature Search}

The literature search produced 223 published articles. After applying our selection criteria, we found 41 randomized controlled trials conducted for prevention and/or treatment of cerebral vasospasm to be eligible for review.

\section{Characteristics of Articles on Vasospasm Therapy}

Characteristics of the studies are summarized in Table 1. There were slight increases in the numbers of studies published for each 5-year period during the time of investigation of calcium channel antagonists and tirilazad. Sample sizes have often been large, particularly considering the relative rarity of SAH, and this is due to the large number of multicenter trials. Sixteen different treatments have been tested, the most frequent being calcium channel antagonists and tirilazad. Most studies included patients with all grades of SAH. Specific information about the timing of surgery was often omitted. The studies included more patients undergoing clip placements than endovascular treatments, but the latter methods were developed only lately and have been included in more recent studies. In $66 \%$ of studies, patients received follow-up care for 3 or more months. Outcome measures, however, were quite variable. A randomization method was described in 54\%, with stratification in multicenter studies in 52\%. Patients were lost to follow up in $22 \%$ of the studies reviewed, intention-to-treat analysis was done in only $49 \%$, the method of blinding was stated in 56\%, and formal power calculations were described in only $37 \%$. Baseline characteristics were described and well balanced in $61 \%$ of studies.

\section{Summary of Primary Outcomes}

Forest plots are presented (Fig. 1) for the RR associated with the outcome variables for all studies in which such results were given or could be calculated from the data. In the seven papers that were not included, the authors had presented their results in a manner that did not allow a calculation of the RR. $16,18,21,28,29,48,52$

\section{Specific Therapies}

Calcium Channel Antagonists. We included 10 trials of calcium channel antagonists in which nimodipine or nicardipine were used. Trials of AT877 (fasudil) and magnesium are listed separately because these agents have mechanisms of action other than antagonism of voltage-gated calcium channels. Metaanalysis of these studies has been performed previously and does not need to be repeated here. ${ }^{5,49}$ There is reasonable evidence that oral nimodipine reduces delayed neurological deterioration due to vasospasm as well as infarct frequency and poor outcome, although the mortality rate is not decreased. Nicardipine, however, did not improve outcome. In the main study, 906 patients with recent aneurysmal SAH classified in all grades were randomized to receive either nicardipine or placebo..$^{18}$ It was found that $32 \%$ of patients in the nicardipine group experienced delayed cerebral ischemia compared with $46 \%$ in the placebo group, a significant difference. Infarction rates were 129 $(48 \%)$ of 267 treated patients and $148(51 \%)$ of 289 in those given a placebo, which was not significantly different. Angiograms were obtained 7 to 11 days after SAH in 103 (23\%) of 449 patients who received nicardipine and in 121 $(26 \%)$ of 457 patients who received a placebo.

In this selected and thus potentially biased subset of patients, $33 \%$ of those treated with nicardipine had moderate to severe angiographic vasospasm compared with $51 \%$ in the placebo group. Outcome was identical between the groups, with $57 \%$ of patients attaining a good recovery and $18 \%$ dead. The possible conclusions are as follows: 1 ) vasospasm does not cause infarction or poor outcome; 2) nicardipine has detrimental effects; or 3) rescue therapy improves outcome in patients given a placebo to the same extent that nicardipine helps treated patients. We suggest that the latter conclusion is correct, because delayed cerebral ischemia was less common in the nicardipine-treated group. If nicardipine was detrimental, which would most likely be due to hypotension, then delayed cerebral ischemia should have been at least as common in the nicardipine group, and these patients should have undergone the same or more frequent use of induced hypertension and/or rescue therapy.

Hemodynamic Therapy. We found three randomized controlled trials that were also discussed in prior metaanalyses. ${ }^{50,61}$ The control group in the first study was treated with antihypertensive drugs, which was common practice at that time, but which is a treatment modality that could affect the difference between treated and control patients. ${ }^{51}$ Excluding this trial reduces the number of patients in whom hemodynamic therapy has been well studied to 146 (with 73 each in treatment and control groups). ${ }^{10,30}$ These trials did not show that hypervolemia improved outcome or reduced the incidence of delayed ischemia, and complications were more common in patients treated with hypervolemia. There 


\section{Evidence-based cerebral vasospasm management}

TABLE 1

Literature review of characteristics of randomized clinical trials for prevention and/or treatment of vasospasm*

\begin{tabular}{|c|c|c|}
\hline Characteristic & No. of Trials $(\%)$ & References \\
\hline \multicolumn{3}{|l|}{ publication yr } \\
\hline $1980-1984$ & $4(10)$ & $1,36,51,67$ \\
\hline 1985-1989 & $10(24)$ & $15,20,21,24,35,44-46,53,60$ \\
\hline 1990-1994 & $4(10)$ & $3,18,42,55$ \\
\hline 1995-1999 & $9(22)$ & $4,13,16,17,26,28,29,38,52$ \\
\hline 2000-2004 & $9(22)$ & $10,19,22,30,48,54,57,66,68$ \\
\hline 2005-present & $5(12)$ & $7,32,62-64$ \\
\hline \multicolumn{3}{|l|}{ no. of patients } \\
\hline$<50$ & $8(20)$ & $7,10,32,38,48,51,63,66$ \\
\hline $50-99$ & $7(17)$ & $20,22,30,35,36,45,62$ \\
\hline $100-249$ & $14(34)$ & $1,3,4,13,15,16,19,21,24,42,44,57,67,68$ \\
\hline $250-500$ & $5(12)$ & $52,54,55,60,64$ \\
\hline$>500$ & $7(17)$ & $17,18,26,28,29,46,53$ \\
\hline \multicolumn{3}{|l|}{ no. of centers } \\
\hline one & $17(42)$ & $7,10,22,30,32,35,36,38,42,45,48,51,57,62,66-68$ \\
\hline multiple & $24(59)$ & $1,3,4,13,15-21,24,26,28,29,44,46,52-55,60,63,64$ \\
\hline \multicolumn{3}{|l|}{ duration of study } \\
\hline not reported & $10(24)$ & $7,13,15,21,32,36,45,48,66,67$ \\
\hline $1-2$ yrs & $25(61)$ & $3,4,16-20,22,24,26,28,29,35,38,42,44,46,51-55,60,62,63$ \\
\hline$>2$ yrs & $6(15)$ & $1,10,30,57,64,68$ \\
\hline \multicolumn{3}{|l|}{ therapy evaluated } \\
\hline magnesium sulfate & $3(7)$ & $7,64,66$ \\
\hline statin & $2(5)$ & 32,62 \\
\hline endothelin antagonist & $2(5)$ & 54,63 \\
\hline anticoagulant & $3(7)$ & $19,57,68$ \\
\hline NO donor & $1(2)$ & 48 \\
\hline hemodynamic & $3(7)$ & $10,30,51$ \\
\hline aspirin & $2(5)$ & 22,36 \\
\hline calcium antagonist & $10(24)$ & $1,15,18,24,35,42,44-46,55$ \\
\hline tirilazad mesylate & $5(12)$ & $16,17,26,28,29$ \\
\hline antioxidant & $2(5)$ & 4,52 \\
\hline plasminogen activator & $1(2)$ & 13 \\
\hline calcitonin gene-related peptide & $1(2)$ & 3 \\
\hline steroid & $3(7)$ & $20,21,38$ \\
\hline thromboxane synthetase inhibitor & $1(2)$ & 60 \\
\hline adrenergic-blocking agent & $1(2)$ & 67 \\
\hline dipyridamole & $1(2)$ & 53 \\
\hline \multicolumn{3}{|l|}{ clinical grade on admission } \\
\hline all grades & $19(46)$ & $3,4,7,13,17,18,20,22,26,28,29,35,46,51,53,57,62,64,67$ \\
\hline WFNS I-IV ${ }^{9} \dagger$ & $2(5)$ & 16,54 \\
\hline WFNS $\geq$ III & $1(2)$ & 63 \\
\hline $\mathrm{H} \& \mathrm{H} \mathrm{I}-\mathrm{III}^{23}$ & $4(10)$ & $10,42,45,68$ \\
\hline H \& H II-IV & $3(7)$ & $48,52,66$ \\
\hline H \& H I-IV & 7 (17) & $19,21,24,30,36,38,55$ \\
\hline Fisher $1-4^{14}$ & $1(2)$ & 32 \\
\hline $\mathrm{H} \& \mathrm{H} \geq \mathrm{III}$ & $1(2)$ & 44 \\
\hline neurologically normal & $1(2)$ & 1 \\
\hline$\geq 30$ on $\mathrm{JCS}$ & $1(2)$ & 60 \\
\hline unknown & $1(2)$ & 15 \\
\hline \multicolumn{3}{|l|}{ timing of op post-SAH } \\
\hline NS & $25(61)$ & $3,4,7,15-18,20,21,24,26,28,29,35,36,42,44,46,51,53,54,62,66-68$ \\
\hline$\leq 24 \mathrm{hrs}$ & $2(5)$ & 19,48 \\
\hline$\leq 48 \mathrm{hrs}$ & $4(10)$ & $32,38,57,63$ \\
\hline$\leq 72 \mathrm{hrs}$ & $4(10)$ & $10,13,55,60$ \\
\hline$\leq 96 \mathrm{hrs}$ & $3(7)$ & $22,52,64$ \\
\hline$>96 \mathrm{hrs}$ & $2(5)$ & 30,45 \\
\hline after 24 hrs of drug delivery & $1(2)$ & 1 \\
\hline \multicolumn{3}{|l|}{ type of op } \\
\hline clip occlusion & $30(73)$ & $\begin{array}{l}1,3,4,10,13,15-18,20-22,24,26,29,30,35,36,38,42,44-46,51-53 \\
55,60,63,67\end{array}$ \\
\hline endovascular coil insertion & $1(2)$ & 19 \\
\hline either method & $7(17)$ & $28,32,54,57,64,66,68$ \\
\hline NS or implied & $3(7)$ & $7,48,62$ \\
\hline \multicolumn{3}{|l|}{ timing of therapy relative to op } \\
\hline postop & $12(29)$ & $3,10,13,19,22,30,38,48,55,57,60,63$ \\
\hline preop & $8(20)$ & $1,36,42,44,45,51,53,64$ \\
\hline NS & $14(34)$ & $7,15,16,18,20,26,32,35,46,52,54,62,66,68$ \\
\hline
\end{tabular}


TABLE 1 (continued)

Literature review of characteristics of randomized clinical trials for prevention and/or treatment of vasospasm*

\begin{tabular}{|c|c|c|}
\hline Characteristic & No. of Trials (\%) & References \\
\hline \multicolumn{3}{|l|}{$\begin{array}{l}\text { timing of therapy relative to op } \\
\text { relative to SAH onset }\end{array}$} \\
\hline$\leq 24 \mathrm{hrs}$ & $2(5)$ & 19,48 \\
\hline$\leq 48 \mathrm{hrs}$ & $9(22)$ & $7,17,26,28,29,32,35,38,63$ \\
\hline$\leq 72 \mathrm{hrs}$ & $9(22)$ & $10,13,16,20,45,57,60,62,66,68$ \\
\hline$\leq 96 \mathrm{hrs}$ & $7(17)$ & $1,44,46,52,54,55,64$ \\
\hline$>96 \mathrm{hrs}$ & $4(10)$ & $4,18,22,30$ \\
\hline NS & $5(12)$ & $15,36,42,51,53$ \\
\hline after onset of DINDs & $3(7)$ & $3,21,24$ \\
\hline \multicolumn{3}{|l|}{ duration of FU } \\
\hline finished at discharge & $13(32)$ & $1,15,20,24,32,38,45,48,51,62,63$ \\
\hline $0-3$ mos & $3(7)$ & $17,21,55$ \\
\hline $3 \operatorname{mos}$ & $19(46)$ & $3,4,7,13,16,18,26,28,29,35,44,46,52-54,57,60,64,66$ \\
\hline$>3 \operatorname{mos}$ & $8(20)$ & $10,19,30,36,42,67,68$ \\
\hline \multicolumn{3}{|l|}{ review of cases in multicenter trials } \\
\hline centralized & $16(39)$ & $1,3,4,16-19,24,26,28,29,44,46,52,63,64$ \\
\hline decentralized or NS & $8(20)$ & $13,15,20,21,53-55,60$ \\
\hline \multicolumn{3}{|l|}{ primary outcome variables assessed } \\
\hline no single "primary outcome" described & $7(17)$ & $20,21,38,48,60,67,68$ \\
\hline vasospasm on angiography & $2(5)$ & 13,63 \\
\hline vasospasm on TCD & $1(2)$ & 62 \\
\hline clinical vasospasm & $2(5)$ & 26,51 \\
\hline $\begin{array}{l}\text { clinical vasospasm w/ documented } \\
\text { arterial spasm }\end{array}$ & $2(5)$ & 19,32 \\
\hline cerebral infarction & $1(2)$ & 46 \\
\hline changes in $\mathrm{CBF}$ & $1(2)$ & 30 \\
\hline DINDs & $5(12)$ & $1,4,45,54,64$ \\
\hline \multicolumn{3}{|l|}{ clinical outcome } \\
\hline at $1 \mathrm{mo}$ & $1(2)$ & 55 \\
\hline at $3 \mathrm{mos}$ & $10(24)$ & $3,7,16,18,35,44,52,53,57,66$ \\
\hline at $4 \mathrm{mos}$ & $1(2)$ & 22 \\
\hline at $6 \mathrm{mos}$ & $1(2)$ & 36 \\
\hline at $\geq 1 \mathrm{yr}$ & $2(5)$ & 10,42 \\
\hline deaths/severe deficits at discharge & $2(5)$ & 15,24 \\
\hline death at 3 mos & $3(7)$ & $17,28,29$ \\
\hline \multicolumn{3}{|l|}{ quality-related characteristics } \\
\hline method of randomization reported & $22(54)$ & $2,4,10,13,16-19,22,26,28-30,35,38,44,46,52,55,57,62,64$ \\
\hline patients lost to FU & $9(22)$ & $17,18,26,28,29,53,54,63,68$ \\
\hline intent-to-treat analysis reported & $20(49)$ & $4,10,16-18,22,28-30,32,42,46,48,51,52,54,57,62,63,68$ \\
\hline blinding method reported & $23(56)$ & $1,4,10,13,18,19,21,22,24,26,28-30,35,44,46,48,52,55,62-64,67,68$ \\
\hline $\begin{array}{l}\text { explanation of power calculations } \\
\text { reported }\end{array}$ & $15(37)$ & $3,4,17,18,42,44,46,52-55,57,62-64$ \\
\hline $\begin{array}{l}\text { randomization stratified to equalize treat- } \\
\text { ment btwn centers in multicenter trials }\end{array}$ & - $13(32)$ & $1,13,16-18,26,28,29,44,46,52,55,63$ \\
\hline $\begin{array}{l}\text { baseline characteristics well described } \\
\text { \& balanced }\end{array}$ & $25(61)$ & $\begin{array}{l}1,4,10,13,16-19,21,22,26,28-30,32,42,44,45,52,54,55,57,60 \\
\quad 62-64,68\end{array}$ \\
\hline \multicolumn{3}{|l|}{ sources of funding } \\
\hline government & $4(10)$ & $7,18,30,32$ \\
\hline private & $3(7)$ & $57,62,64$ \\
\hline pharmaceutical company & $14(34)$ & $1,3,16-18,26,28,29,32,44,46,52,54,63$ \\
\hline none stated & $21(51)$ & $4,10,13,15,19,20,22,24,35,36,38,42,45,48,51,53,55,60,66-68$ \\
\hline
\end{tabular}

* CBF = cerebral blood flow; FU = follow up; H \& H = Hunt and Hess; JCS = Japan Coma Scale; NS = not specified; TCD = transcranial Doppler; WFNS = World Federation of Neurosurgical Societies.

$\dagger$ See Drake.

seems to be no evidence to support use of prophylactic hypervolemia in patients with aneurysmal SAH.

Magnesium. There were three studies of therapeutic magnesium infusions in patients with aneurysmal SAH. ${ }^{7,64,66}$ In the largest one, 283 patients were randomized within 4 days of SAH to receive intravenous magnesium sulfate $(64 \mathrm{mmol} / \mathrm{L} / \mathrm{day}$, which is a standard toxemia dose) or intravenous saline. ${ }^{64}$ The primary outcome, delayed cerebral ischemia, was reduced by $34 \%$ after infusion of magnesium (hazard ratio $0.66,95 \%$ CI $0.38-1.14$ ).
There also were favorable trends in the magnesium-treated group in terms of reduction in poor outcome at 3 months $(23 \%$ risk reduction, risk ratio $0.77,95 \% \mathrm{CI}$ 0.54-1.09). There were two studies, which included 4066 and 45 patients. ${ }^{7}$ These studies provide some evidence for the safety and feasibility of maintaining elevated serum levels of magnesium.

Statins. There were two small studies in which patients with SAH were randomized to a group receiving a hydroxymethylglutaryl coenzyme A reductase inhibitor 
Evidence-based cerebral vasospasm management

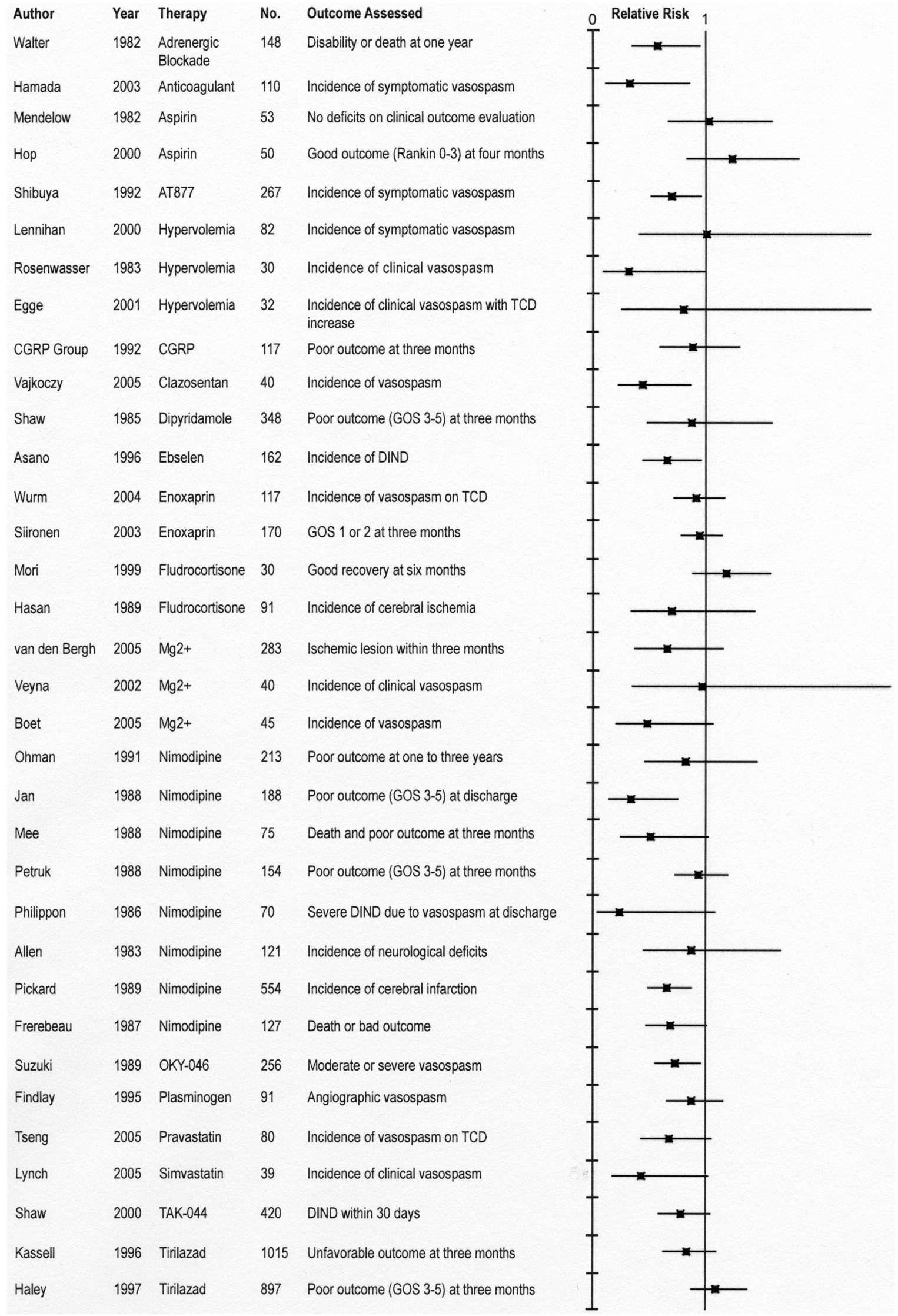

FIG. 1. Forest plot showing RRs of adverse outcome as defined in the particular study. CGRP = calcitonin gene-related peptide. 
(statin; either simvastatin [19 patients] or pravastatin [40 patients]) and a group of 70 patients who received a placebo. ${ }^{32,62}$ Statin therapy was associated in both studies with a significant reduction in evidence of vasospasm on transcranial Doppler ultrasonography, and in the larger study, in which pravastatin was used, with reduced duration of severe vasospasm and a reduced overall mortality rate. ${ }^{62}$

Endothelin Antagonists. A nonselective endothelin receptor antagonist, TAK-044, was compared with a placebo in a randomized blinded trial of 420 patients treated within 96 hours of SAH. ${ }^{54}$ There was a trend toward a reduction in ischemic events in the treated patients $(23 \%$ with placebo, 21\% with TAK-044; not significant) but no significant differences in outcome or overall deaths. Patients receiving TAK-044 had significantly more hypotensive episodes necessitating increased use of vasopressor drugs (16\% compared with $7 \%$ in the placebo group).

A small clinical trial of clazosentan, an endothelin A receptor-specific antagonist, was recently reported ${ }^{63}$ In this study, 32 patients with thick aneurysmal SAH were randomly allocated to receive placebo or clazosentan. Angiographically confirmed vasospasm occurred in $88 \%$ of those who received placebo but in only $40 \%$ of clazosentan-treated patients $(p=0.008)$. Furthermore, the severity of vasospasm was reduced by clazosentan, reversal of established vasospasm was documented angiographically after selective intraarterial infusions, and there was a trend toward reduction in the incidence of cerebral infarction in treated patients.

Intracisternal Fibrinolysis. Findlay, et al., ${ }^{13}$ conducted the only randomized study of intracisternal fibrinolysis with tissue plasminogen activator. Although there was no significant effect on the prespecified primary end point of angiographically confirmed vasospasm, there was a trend for vasospasm to be less severe in treated patients. In the subset of patients with thick SAH on admission CT scans, there was a 56\% reduction in the RR of severe vasospasm in the fibrinolysis-treated patients $(\mathrm{p}=0.02)$.

Anticoagulation Therapy. The low-molecular-weight heparin enoxaparin has been studied in two randomized controlled trials. Wurm and colleagues ${ }^{68}$ reported a remarkable reduction in cerebral infarction caused by vasospasm, from $28 \%$ in patients receiving placebo to $9 \%$ in treated patients, in association with reductions in the following phenomena: vasospasm, poor outcome at 1 year, shunt-dependent hydrocephalus, and intracranial hemorrhagic complications. In the second study, Siironen and colleagues ${ }^{57}$ found no significant difference in outcome at 3 months between the group given a placebo and enoxaparin-treated patients on the GOS and modified Rankin Scale.

Other Treatments. Tirilazad was studied in four trials. ${ }^{17,26,28,29}$ Although a formal metaanalysis has not been published, we analyzed the raw data in the 3567 patients participating in these trials and found that the odds of poor outcome were 1.04 with tirilazad compared with placebo (95\% CI 0.94-1.16). Steroid drugs were studied in three trials that included 256 patients..$^{20,21,38}$ In two studies mineralocorticoids were used, which have different actions from the glucocorticoids that were used in the third study. ${ }^{21}$ On metaanalysis it was found that mineralocorticoid treatment reduced the risk of delayed ischemia (RR
$0.65,95 \%$ CI $0.33-1.27$ ) and poor outcome (RR 0.33, 95\% CI 0.03-3.02). ${ }^{11}$ Side effects were higher with treatment (RR 1.75, 95\% CI 1.03-2.95) when examining all three studies, and there was no significant effect on outcome.

There are only very limited data available for other treatments, such as aspirin, ${ }^{22,36} \mathrm{NO}$ donors, ${ }^{48}$ other antioxidants, ${ }^{4,52}$ calcitonin gene-related peptide, ${ }^{3}$ thromboxane synthase inhibitors, ${ }^{60}$ adrenergic antagonists, ${ }^{67}$ and dipyridamole..$^{53}$

\section{Discussion}

\section{Quality of Studies}

Guidelines for reporting the results of randomized control trials (CONSORT Statement) have been published. ${ }^{6,37}$ The guidelines include a checklist of 22 items that should be included in the published report of a clinical trial. Researchers evaluated SAH trials published between 1990 and 1999 in 10 major journals, and based on these guidelines, they concluded that the majority of studies on treatment strategies for SAH do not meet the requirements for proper methods. ${ }^{65}$ This implies that treatment recommendations for SAH are based on weak evidence.

Table 1 characterizes the vasospasm literature on the basis of several of the key quality measures. The small size of many of these studies mitigated some common problems such as lack of follow-up review for patients. Only $22 \%$ of the studies reported any patients lost to follow up, and generally these losses were small and balanced between study arms. However, randomization methods were reported in only half $(54 \%)$ of the papers, few $(37 \%)$ gave information on power calculations, and measures taken to ensure blinding were well reported in only $56 \%$ of studies. Intention-to-treat analysis was used in $49 \%$ of papers and, importantly, in the majority of the nimodipine papers large numbers of patients were eliminated in blinded reviews after randomization. Reporting of baseline characteristics was problematic; there was a high degree of inconsistency in the variables reported, and in $39 \%$ of the papers these variables were not well described or were not balanced between treatment and control groups. No papers included a multivariate analysis to correct for imbalances in the baseline characteristics. Of the multicenter trials, only $52 \%$ report a method used to stratify the randomization of patients at each center to prevent center-specific treatment procedures from confounding the results. Other measures that are related to quality were disclosure of funding sources and identification of a primary outcome (Table 1). Funding sources were reported in only $49 \%$ of studies and a primary outcome was not identified either explicitly or implicitly in $17 \%$ of the papers.

It is important to consider that this review includes papers that were published as far back as the early 1980s, predating the CONSORT guidelines, and thus an evaluation based on modern criteria may seem unwarranted. Nevertheless, some clinical trials that guide current clinical practice (for example, trials of calcium channel antagonists) were published prior to the CONSORT guidelines. Additionally, there were discussions about the proper or- 
ganization and reporting of clinical trials long before the CONSORT statement was issued. In the articles reviewed here, there were examples of improper reporting both before and after 1996, and thus there was not a dramatic shift in the quality of trials over this time. Therefore, close adherence to common reporting procedures is recommended and would improve the quality of randomized controlled trials of vasospasm therapy.

\section{Prior Metaanalyses}

The randomized trials of nimodipine and nicardipine have been subjected to at least two metaanalyses. Barker and Ogilvy ${ }^{5}$ included seven nimodipine studies in which 1202 patients were randomized. Nimodipine improved the odds of good and good plus fair outcome (odds ratios 1.9 and 1.7 , respectively; $p<0.005$ for both) and reduced the odds of neurological deficit and/or death attributed to vasospasm by $0.46(\mathrm{p}<0.008)$. The finding of infarction on CT scans also was reduced by $0.58(\mathrm{p}<0.008)$, although the mortality rate was not altered significantly. In the Cochrane collaboration, investigators reviewed 12 studies that included nimodipine, nicardipine, AT877, and magnesium, and made a somewhat weak recommendation for use of nimodipine by stating that the evidence in its favor was not proven beyond reasonable doubt, but that they recommended its use in view of the favorable benefit/toxicity ratio. ${ }^{49}$ We would make a stronger recommendation for its use for at least 14 days after SAH in all cases, except in patients with no visible $\mathrm{SAH}$ on $\mathrm{CT}$ scans or who can be discharged home sooner. These investigators also stated that there is no evidence that nicardipine or AT877 have significant effects on outcome post-SAH, with which we concur, and which supports a recommendation that these drugs not be used for this indication at present.

Another method of vasospasm management subjected to metaanalysis was hemodynamic therapy; there are two metaanalyses of the three randomized trials. ${ }^{50,61}$ These studies focused on prophylactic hypervolemia, and the effects of induced hypertension and hemodilution could not be discerned. The works in question also were compromised by use of pharmacologically induced hypotension in the control group in one study ${ }^{51}$ and by different target hematocrits. Rinkel, et al., ${ }^{50}$ who analyzed the three studies included here, reported that hypervolemia did not improve outcome or reduce the incidence of delayed ischemia. In fact, complications were more common in patients treated with hypervolemia. The authors concluded that there was no evidence for effectiveness of prophylactic hypervolemia, and they recommended that more clinical trials of volume expansion therapy be conducted. Hemodynamic manipulations were used both prophylactically and therapeutically at most centers in the US in the 1990s. For example, in the four randomized trials of tirilazad conducted between 1991 and 1997, 63\% of the approximately 3500 patients underwent prophylactic hemodynamic manipulations and 23\% were treated with hemodynamic therapy. ${ }^{17,26,28,29}$ Any future trials of hemodynamic therapy would have to consider whether to address prophylactic or therapeutic aspects, and which maneuver or combination thereof to study, and would also have to take into account flexibility in treatment regimens that would be acceptable to neurosurgeons.

\section{Other Treatments}

The efficacy of magnesium is still in question. A randomized blinded clinical trial is underway (Intravenous Magnesium Sulfate in Aneurysmal Subarachnoid Hemorrhage Trial) and is scheduled to be completed in November 2007, with a total of 500 patients randomized. Although the clinical trial of magnesium for ischemic stroke did not demonstrate efficacy, ${ }^{39}$ there are numerous potential beneficial effects of magnesium, including vasodilation and neuroprotection. The cost is low, the therapeutic index is broad, and administration is simple. In $\mathrm{SAH}$, treatment can begin before onset of ischemia, so there is a compelling rationale for the Intravenous Magnesium Sulfate in Aneurysmal Subarachnoid Hemorrhage Trial. Whether to use therapeutic infusions is open to question at present.

The promising results of the two statin trials were corroborated by a retrospective cohort study of 20 patients with SAH who were admitted to the hospital while being treated with statins and 40 control cases of SAH..$^{43}$ Patients receiving statin therapy had a better functional outcome and were less likely to suffer delayed cerebral ischemia, although there was no effect on the mortality rate. However, Singhal, et al. ${ }^{58}$ noted in a similar retrospective observational study that patients with $\mathrm{SAH}$ who were admitted while undergoing statin therapy had an increased risk of vasospasm, and they speculated that this might be due to abrupt discontinuation of the drug on hospital admission for SAH. Statins have a host of biochemical effects that may benefit patients with $\mathrm{SAH}$, including increasing endothelial nitric oxide synthase, enhancing bioavailability of NO, decreasing oxidative stress, inhibiting thrombogenesis, and reducing inflammation. ${ }^{31}$ Risks are low and definitive clinical trials are strongly recommended. We suggest awaiting results of these studies before initiating widespread use of statins.

There is much interest in trials of endothelin antagonists. Evidence obtained from experimental models of SAH and clinical studies of endothelin concentrations in humans with SAH support the suggestion that alterations in the vasoconstricting endothelin system might contribute to vasospasm. ${ }^{70}$ Although results of the first study with a nonselective receptor antagonist were unimpressive, ${ }^{54}$ the selective endothelin A receptor antagonist clazosentan was strikingly effective, albeit in a very small trial. ${ }^{63}$ There are theoretical reasons why antagonists that are selective for the A receptor may be more effective against vasospasm. The results of a Phase IIb trial of clazosentan, in which patient recruitment stopped in November 2006 after approximately 400 patients were enrolled, should be available soon. Only bosentan is commercially available, but it is not recommended for use in patients with $\mathrm{SAH}$ at present.

There is abundant experimental and clinical evidence to support the hypothesis that vasospasm is related in a dose-response fashion to the location, volume, density (denser clots have more of whatever spasmogen is in the clot, or they incite more of the reaction that causes vasospasm), and rate of clearance of SAH. ${ }^{12,47,69}$ Therefore, it is highly likely that if one could safely and effectively remove the hematoma quickly after the onset of SAH, then vasospasm would be reduced. Fibrinolytic therapy was 
G. W. Weyer, C. P. Nolan, and R. L. Macdonald

subjected to metaanalysis that included nine trials. ${ }^{2}$ All but one study were nonrandomized, unblinded trials of the type that are known for a tendency to overestimate efficacy and underestimate side effects. The metaanalysis indicated that these treatments have a favorable impact on development of DINDs, GOS score, and overall mortality rate. However, the results of the only randomized control trial, ${ }^{13}$ although they were within the $95 \%$ CIs for the pooled analysis, were at odds with the nonrandomized studies. Fibrinolytic therapy shows promise for the prevention of vasospasm, but the current level of evidence is weak and a large randomized controlled trial is needed. We do use intracisternal fibrinolytic therapy in selected patients with SAH whose ruptured aneurysms are definitely occluded and who have persistent SAH after aneurysm treatment.

It seems unlikely that enoxaparin will have any significant, measurable effect on outcome after SAH. At present, there is little evidence that can serve as a rationale for using anticoagulant agents specifically for prevention of vasospasm. There might be more support for their use in the prevention of venous thromboembolic complications, but even here, the question is whether this benefit is offset by an increased risk of hemorrhage. This question has been addressed in a previous review focusing on anticoagulation therapy in the context of head and spinal cord injury. ${ }^{33}$

Trials of tirilazad included the most patients ever studied in randomized controlled SAH trials. ${ }^{17,26,28,29} \mathrm{~A}$ formal metaanalysis of the studies has not been published, but we have analyzed the raw data from these trials and found no evidence of an effect on outcome. Analysis of effects on symptomatic vasospasm and infarction need to be completed. Metaanalysis of the three trials of steroid drugs for treatment of SAH found no evidence for efficacy, and instead there was a suggestion of increased complications. ${ }^{11}$ It was recommended that additional studies be performed. We do not use glucocorticoid agents in patients with SAH, nor do we have much interest in such studies.

It is difficult to say whether to pursue antiplatelet therapy for SAH. The experimental data in support of its use are weak at present, and these drugs would probably be associated with an increased risk of intracranial hemorrhage.

\section{Conclusions}

The only proven therapy for vasospasm is nimodipine; tirilazad is not effective. More study of hemodynamic maneuvers, other calcium channel antagonists such as nicardipine delivered by other routes such as intrathecally, ${ }^{27}$ magnesium, statin drugs, endothelin antagonists, and intrathecal fibrinolytic medications is warranted. There is less enthusiasm for the study of steroid drugs and anticoagulant/antiplatelet agents because they entail more risks, and studies so far have shown little evidence of efficacy. The study of rescue therapy such as balloon angioplasty and intraarterial vasodilating agents will be difficult. The quality of clinical trials should be improved.

\section{Disclosure}

Dr. Macdonald received grant support from Boston Scientific and consultant fees from Actelion Pharmaceuticals.

\section{References}

1. Allen GS, Ahn HS, Preziosi TJ, Battye TJ, Boone SC, Boone $\mathrm{SC}$, et al: Cerebral arterial spasm-a controlled trial of nimodipine in patients with subarachnoid hemorrhage. $\mathbf{N}$ Engl J Med 308:619-624, 1983

2. Amin-Hanjani S, Ogilvy CS, Barker FG II: Does intracisternal thrombolysis prevent vasospasm after aneurysmal subarachnoid hemorrhage? A meta-analysis. Neurosurgery 54: 326-334, 2004

3. Anonymous: Effect of calcitonin-gene-related peptide in patients with delayed postoperative cerebral ischaemia after aneurysmal subarachnoid haemorrhage. European CGRP in Subarachnoid Haemorrhage Study Group. Lancet 339: 831-834, 1992

4. Asano T, Takakura K, Sano K, Kikuchi H, Nagai H, Saito I, et al: Effects of a hydroxyl radical scavenger on delayed ischemic neurological deficits following aneurysmal subarachnoid hemorrhage: results of a multicenter, placebo-controlled doubleblind trial. J Neurosurg 84:792-803, 1996

5. Barker FG II, Ogilvy CS: Efficacy of prophylactic nimodipine for delayed ischemic deficit after subarachnoid hemorrhage: a metaanalysis. J Neurosurg 84:405-414, 1996

6. Begg C, Cho M, Eastwood S, Horton R, Moher D, Olkin I, et al: Improving the quality of reporting of randomized controlled trials. The CONSORT statement. JAMA 276:637-639, 1996

7. Boet R, Chan MT, Poon WS, Wong GT, Gin T: Intravenous magnesium sulfate to improve outcome after aneurysmal subarachnoid hemorrhage: interim report from a pilot study. Acta Neurochir Suppl 95:263-264, 2005

8. Cook DJ, Guyatt GH, Laupacis A, Sackett DL: Rules of evidence and clinical recommendations on the use of antithrombotic agents. Chest 102 (Suppl):305S-311S, 1992

9. Drake CG: Report of World Federation of Neurological Surgeons Committee on a universal subarachnoid hemorrhage grading scale. J Neurosurg 68:985-986, 1988

10. Egge A, Waterloo K, Sjoholm H, Solberg T, Ingelbrigtsen $T$, Romner B: Prophylactic hyperdynamic postoperative fluid therapy after aneurysmal subarachnoid hemorrhage: a clinical, prospective, randomized, controlled study. Neurosurgery 49: 593-605, 2001

11. Feigin V, Anderson N, Rinkel G, Algra A, van Gijn J, Bennett DA: Corticosteroids for aneurysmal subarachnoid haemorrhage and primary intracerebral haemorrhage. Cochrane Database Syst Rev:CD004583, 2005

12. Findlay JM: Intrathecal thrombolytic therapy in the prevention of vasospasm following subarachnoid hemorrhage, in Sawaya $R$ (ed): Fibrinolysis and the Central Nervous System. Philadelphia: Hanley \& Belfus, 1990, pp 203-212

13. Findlay JM, Kassell NF, Weir BK, Haley EC Jr, Kongable G, Germanson $\mathrm{T}$, et al: A randomized trial of intraoperative, intracisternal tissue plasminogen activator for the prevention of vasospasm. Neurosurgery 37:168-178, 1995

14. Fisher CM, Kistler JP, Davis JM: Relation of cerebral vasospasm to subarachnoid hemorrhage visualized by computerized tomographic scanning. Neurosurgery 6:1-9, 1980

15. Frerebeau P, Janny P, Taquoi G, Besson G, Buchheit F, Childs $\mathrm{M}$, et al: [Treatment of vasospasm in aneurysmal meningeal hemorrhage using intravenous nimodipine. Multicenter cooperative study.] Neurochirurgie 34:383-388, 1988 (Fr)

16. Haley EC Jr, Kassell NF, Alves WM, Weir BK, Hansen CA: Phase II trial of tirilazad in aneurysmal subarachnoid hemorrhage. A report of the Cooperative Aneurysm Study. J Neurosurg 82:786-790, 1995

17. Haley EC Jr, Kassell NF, Apperson-Hansen C, Maile MH, Alves WM: A randomized, double-blind, vehicle-controlled trial of tirilazad mesylate in patients with aneurysmal subarachnoid hemorrhage: a cooperative study in North America. J Neurosurg 86:467-474, 1997 
18. Haley EC Jr, Kassell NF, Torner JC: A randomized controlled trial of high-dose intravenous nicardipine in aneurysmal subarachnoid hemorrhage. A report of the Cooperative Aneurysm Study. J Neurosurg 78:537-547, 1993

19. Hamada JI, Kai Y, Morioka M, Yano S, Mizuno T, Hirano T, et al: Effect on cerebral vasospasm of coil embolization followed by microcatheter intrathecal urokinase infusion into the cisterna magna. A prospective randomized study. Stroke 34:2549, 2003

20. Hasan D, Lindsay KW, Wijdicks EFM, Murray GD, Brouwers PJ, Bakker WH, et al: Effect of fludrocortisone acetate in patients with subarachnoid hemorrhage. Stroke 20:1156-1161, 1989

21. Hashi K, Takakura K, Sano K, Ohta T, Saito I, Okada K: Intravenous hydrocortisone in large doses for the treatment of delayed ischemic neurological deficits following subarachnoid hemorrhage - results of a multi-center controlled double-blind clinical study. No to Shinkei 40:373-382, 1988

22. Hop JW, Rinkel GJ, Algra A, Berkelbach van der Sprenkel JW, van Gijn J: Randomized pilot trial of postoperative aspirin in subarachnoid hemorrhage. Neurology 54:872-878, 2000

23. Hunt WE, Hess RM: Surgical risk as related to time of intervention in the repair of intracranial aneurysms. J Neurosurg 28: 14-20, 1968

24. Jan M, Buchheit F, Tremoulet M: Therapeutic trial of intravenous nimodipine in patients with established cerebral vasospasm after rupture of intracranial aneurysms. Neurosurgery 23:154-157, 1988

25. Kassell NF: The role of vasospasm in overall outcome from aneurysmal subarachnoid hemorrhage, in Findlay JM (ed): Cerebral Vasospasm. Amsterdam: Elsevier, 1993, pp 27-28

26. Kassell NF, Haley EC Jr, Apperson-Hansen C, Alves WM: Randomized, double-blind, vehicle-controlled trial of tirilazad mesylate in patients with aneurysmal subarachnoid hemorrhage: a cooperative study in Europe, Australia, and New Zealand. J Neurosurg 84:221-228, 1996

27. Kasuya H, Onda H, Sasahara A, Takeshita M, Hori T: Application of nicardipine prolonged-release implants: analysis of 97 consecutive patients with acute subarachnoid hemorrhage. Neurosurgery 56:895-902, 2005

28. Lanzino G, Kassell NF: Double-blind, randomized, vehiclecontrolled study of high-dose tirilazad mesylate in women with aneurysmal subarachnoid hemorrhage. Part II. A cooperative study in North America. J Neurosurg 90:1018-1024, 1999

29. Lanzino G, Kassell NF, Dorsch NW, Pasqualin A, Brandt L, Schmiedek P, et al: Double-blind, randomized, vehicle-controlled study of high-dose tirilazad mesylate in women with aneurysmal subarachnoid hemorrhage. Part I. A cooperative study in Europe, Australia, New Zealand, and South Africa. J Neurosurg 90:1011-1017, 1999

30. Lennihan L, Mayer SA, Fink ME, Beckford A, Paik MC, Zhang $\mathrm{H}$, et al: Effect of hypervolemic therapy on cerebral blood flow after subarachnoid hemorrhage: a randomized controlled trial. Stroke 31:383-391, 2000

31. Liao JK, Laufs U: Pleiotropic effects of statins. Annu Rev Pharmacol Toxicol 45:89-118, 2005

32. Lynch JR, Wang H, McGirt MJ, Floyd J, Friedman AH, Coon $\mathrm{AL}$, et al: Simvastatin reduces vasospasm after aneurysmal subarachnoid hemorrhage: results of a pilot randomized clinical trial. Stroke 36:2024-2026, 2005

33. Macdonald RL: What is the safest way to prevent deep venous thrombosis and pulmonary embolism after head or spinal cord injury? How soon after surgery or injury can I anticoagulate my patients who develop deep venous thrombosis?, in Valadka AB, Andrews BT (eds): Neurotrauma. Evidence-Based Answers to Common Questions. New York: Thieme, 2005, pp 43-49

34. Macdonald RL, Weir B: Cerebral vasospasm: prevention and treatment, in Batjer HH, Caplan LR, Friberg L, et al: (eds): Cerebrovascular Disease. Philadelphia: Lippincott-Raven, 1997, pp 1111-1121
35. Mee E, Dorrance D, Lowe D, Neil-Dwyer G, et al: Controlled study of nimodipine in aneurysm patients treated early after subarachnoid hemorrhage. Neurosurgery 22:484-491, 1988

36. Mendelow AD, Stockdill G, Steers AJ, Hayes J, Gillingham FJ: Double-blind trial of aspirin in patient receiving tranexamic acid for subarachnoid hemorrhage. Acta Neurochir (Wien) 62: $195-202,1982$

37. Moher D, Schulz KF, Altman D: The CONSORT statement: revised recommendations for improving the quality of reports of parallel-group randomized trials. JAMA 285:1987-1991, 2001

38. Mori T, Katayama Y, Kawamata T: Improved efficiency of hypervolemic therapy with inhibition of natriuresis by fludrocortisone in patients with aneurysmal subarachnoid hemorrhage. J Neurosurg 91:947-952, 1999

39. Muir KW, Lees KR, Ford I, Davis S: Magnesium for acute stroke (Intravenous Magnesium Efficacy in Stroke Trial): randomised controlled trial. Lancet 363:439-445, 2004

40. Newcombe RG: Two-sided confidence intervals for the single proportion: comparison of seven methods. Stat Med 17: 857-872, 1998

41. Ohkuma H, Tsurutani H, Suzuki S: Changes of beta-actin mRNA expression in canine vasospastic basilar artery after experimental subarachnoid hemorrhage. Neurosci Lett 311: 9-12, 2001

42. Ohman J, Servo A, Heiskanen O: Long-term effects of nimodipine on cerebral infarcts and outcome after aneurysmal subarachnoid hemorrhage and surgery. J Neurosurg 74:8-13, 1991

43. Parra A, Kreiter KT, Williams S, Sciacca R, Mack WJ, Naidech AM, et al: Effect of prior statin use on functional outcome and delayed vasospasm after acute aneurysmal subarachnoid hemorrhage: a matched controlled cohort study. Neurosurgery 56: 476-484, 2005

44. Petruk KC, West M, Mohr G, Weir BK, Benoit BG, Gentili F, et al: Nimodipine treatment in poor-grade aneurysm patients. Results of a multicenter double-blind placebo-controlled trial. J Neurosurg 68:505-517, 1988

45. Philippon J, Grob R, Dagreou F, Guggiari M, Rivierez M, Viars P: Prevention of vasospasm in subarachnoid haemorrhage. A controlled study with nimodipine. Acta Neurochir (Wien) 82: 110-114, 1986

46. Pickard JD, Murray GD, Illingworth R, Shaw MD, Teasdale GM, Foy PM, et al: Effect of oral nimodipine on cerebral infarction and outcome after subarachnoid haemorrhage: British aneurysm nimodipine trial. BMJ 298:636-642, 1989

47. Reilly C, Amidei C, Tolentino J, Jahromi BS, Macdonald RL: Clot volume and clearance rate as independent predictors of vasospasm after aneurysmal subarachnoid hemorrhage. J Neurosurg 101:255-261, 2004

48. Reinert M, Wiest R, Barth L, Andres R, Ozdoba C, Seiler R: Transdermal nitroglycerin in patients with subarachnoid hemorrhage. Neurol Res 26:435-439, 2004

49. Rinkel GJ, Feigin VL, Algra A, van den Bergh WM, Vermeulen M, van Gijn J: Calcium antagonists for aneurysmal subarachnoid haemorrhage. Cochrane Database Syst Rev:CD000277, 2005

50. Rinkel GJ, Feigin VL, Algra A, van Gijn J: Circulatory volume expansion therapy for aneurysmal subarachnoid haemorrhage. Cochrane Database Syst Rev:CD000483, 2004

51. Rosenwasser RH, Delgado TE, Buchheit WA, Freed MH: Control of hypertension and prophylaxis against vasospasm in cases of subarachnoid hemorrhage: a preliminary report. Neurosurgery 12:658-661, 1983

52. Saito I, Asano T, Sano K, Takakura K, Abe H, Yoshimoto T, et al: Neuroprotective effect of an antioxidant, ebselen, in patients with delayed neurological deficits after aneurysmal subarachnoid hemorrhage. Neurosurgery 42:269-278, 1998

53. Shaw MD, Foy PM, Conway M, Pickard JD, Maloney P, Spillane JA, et al: Dipyridamole and postoperative ischemic deficits in aneurysmal subarachnoid hemorrhage. J Neurosurg 63: 699-703, 1985 
54. Shaw MD, Vermeulen M, Murray GD, Pickard JD, Bell BA, Teasdale GM: Efficacy and safety of the endothelin, receptor antagonist TAK-044 in treating subarachnoid hemorrhage: a report by the Steering Committee on behalf of the UK/Netherlands/Eire TAK-044 Subarachnoid Haemorrhage Study Group. J Neurosurg 93:992-997, 2000

55. Shibuya M, Suzuki Y, Sugita K, Saito K, Sasaki T, Takakura K, et al: Effect of AT877 on cerebral vasospasm after aneurysmal subarachnoid hemorrhage. Results of a prospective placebocontrolled double-blind trial. J Neurosurg 76:571-577, 1992

56. Shimoda M, Takeuchi M, Tominaga J, Oda S, Kumasaka A, Tsugane R: Asymptomatic versus symptomatic infarcts from vasospasm in patients with subarachnoid hemorrhage: serial magnetic resonance imaging. Neurosurgery 49:1341-1350, 2001

57. Siironen J, Juvela S, Varis J, Porras M, Poussa K, Ilveskero S, et al: No effect of enoxaparin on outcome of aneurysmal subarachnoid hemorrhage: a randomized, double-blind, placebocontrolled clinical trial. J Neurosurg 99:953-959, 2003

58. Singhal AB, Topcuoglu MA, Dorer DJ, Ogilvy CS, Carter BS, Koroshetz WJ: SSRI and statin use increases the risk for vasospasm after subarachnoid hemorrhage. Neurology 64: 1008-1013, 2005

59. Suarez JI, Tarr RW, Selman WR: Aneurysmal subarachnoid hemorrhage. N Engl J Med 354:387-396, 2006

60. Suzuki S, Sano K, Handa H, Asano T, Tamura A, Yonekawa Y, et al: Clinical study of OKY-046, a thromboxane synthetase inhibitor, in prevention of cerebral vasospasms and delayed cerebral ischaemic symptoms after subarachnoid haemorrhage due to aneurysmal rupture: a randomized double-blind study. Neurol Res 11:79-88, 1989

61. Treggiari MM, Walder B, Suter PM, Romand JA: Systematic review of the prevention of delayed ischemic neurological deficits with hypertension, hypervolemia, and hemodilution therapy following subarachnoid hemorrhage. J Neurosurg 98: 978-984, 2003

62. Tseng MY, Czosnyka M, Richards H, Pickard JD, Kirkpatrick PJ: Effects of acute treatment with pravastatin on cerebral vasospasm, autoregulation, and delayed ischemic deficits after aneurysmal subarachnoid hemorrhage: a phase II randomized placebo-controlled trial. Stroke 36:1627-1632, 2005
G. W. Weyer, C. P. Nolan, and R. L. Macdonald

63. Vajkoczy P, Meyer B, Weidauer S, Raabe A, Thome C, Ringel F, et al: Clazosentan (AXV-034343), a selective endothelin A receptor antagonist, in the prevention of cerebral vasospasm following severe aneurysmal subarachnoid hemorrhage: results of a randomized, double-blind, placebo-controlled, multicenter phase IIa study. J Neurosurg 103:9-17, 2005

64. van den Bergh WM, Algra A, van Kooten F, Dirven CM, van Gijn J, Vermeulen M, et al: Magnesium sulfate in aneurysmal subarachnoid hemorrhage: a randomized controlled trial. Stroke 36:1011-1015, 2005

65. van der Schaaf I, Ruigrok YM, Rinkel GJ, Algra A, van Gijn J: Study design and outcome measures in studies on aneurysmal subarachnoid hemorrhage. Stroke 33:2043-2046, 2002

66. Veyna RS, Seyfried D, Burke DG, Zimmerman C, Mlynarek M, Nichols V, et al: Magnesium sulfate therapy after aneurysmal subarachnoid hemorrhage. J Neurosurg 96:510-514, 2002

67. Walter P, Neil-Dwyer G, Cruickshank JM: Beneficial effects of adrenergic blockade in patients with subarachnoid haemorrhage. Br Med J (Clin Res Ed) 284:1661-1664, 1982

68. Wurm G, Tomancok B, Nussbaumer K, Adelwohrer C, Holl K: Reduction of ischemic sequelae following spontaneous subarachnoid hemorrhage: a double-blind, randomized comparison of enoxaparin versus placebo. Clin Neurol Neurosurg 106: 97-103, 2004

69. Zhang ZD, Yamini B, Komuro T, Ono S, Johns L, Marton LS, et al: Vasospasm in monkeys resolves because of loss of and encasement of subarachnoid blood clot. Stroke 32:1868-1874, 2001

70. Zimmermann M, Seifert V: Endothelin and subarachnoid hemorrhage: an overview. Neurosurgery 43:863-876, 1998

Manuscript received June 16, 2006.

Accepted in final form August 4, 2006.

Drs. Nolan and Macdonald are supported by grants from the National Institutes of Health (RO1 NS25946) and the American Heart Association.

Address reprint requests to: R. Loch Macdonald, M.D, Section of Neurosurgery, MC3026, 5841 South Maryland Avenue, Chicago, Illinois 60637. email: rlmacdon@uchicago.edu. 